\section{Hepatobiliary candidiasis in chronic lymphatic leukaemia}

A 64 year old woman with longstanding chronic lymphatic leukaemia presented after six weeks' fever and cough. On examination she had a fever and severe oral candidiasis, signs of pneumonia, mild jaundice, and tender hepatomegaly. A chest $x$ ray film showed bilateral interstitial pneumonia. Ultrasonography and subsequent endoscopic retrograde cholangiopancreatographic examination showed a widespread intraductal biliary cast (white arrows) and multiple small communicating microabscesses (black arrows) (figure). Ultrasound guided biopsy and microscopy showed fungal mycelia, later identified as Candida albicans. Despite intensive antifungal treatment she died of overwhelming infection eight weeks later. Severe systemic fungal infections are being recognised increasingly in immunosuppressed patients.' Computed tomography and ultrasonography are the most sensitive methods for imaging and guided needle biopsy of hepatic and splenic microabscesses. Biliary disease is rare, and the findings here mimicking the thrombus in haemobilia are previously undescribed.-C N HACKING, M J GOODRICK, M CHISHOLM, departments of radiology and haematology, Southampton General Hospital, Southampton SO9 4XY.

1 Haron E, Feld R, Tuffnell P, Patterson B, Hasselback R, Matlow A. Hepatic candidiasis: an increasing problem in immunocompromised patients. Am Med f 1987;8:17-26.

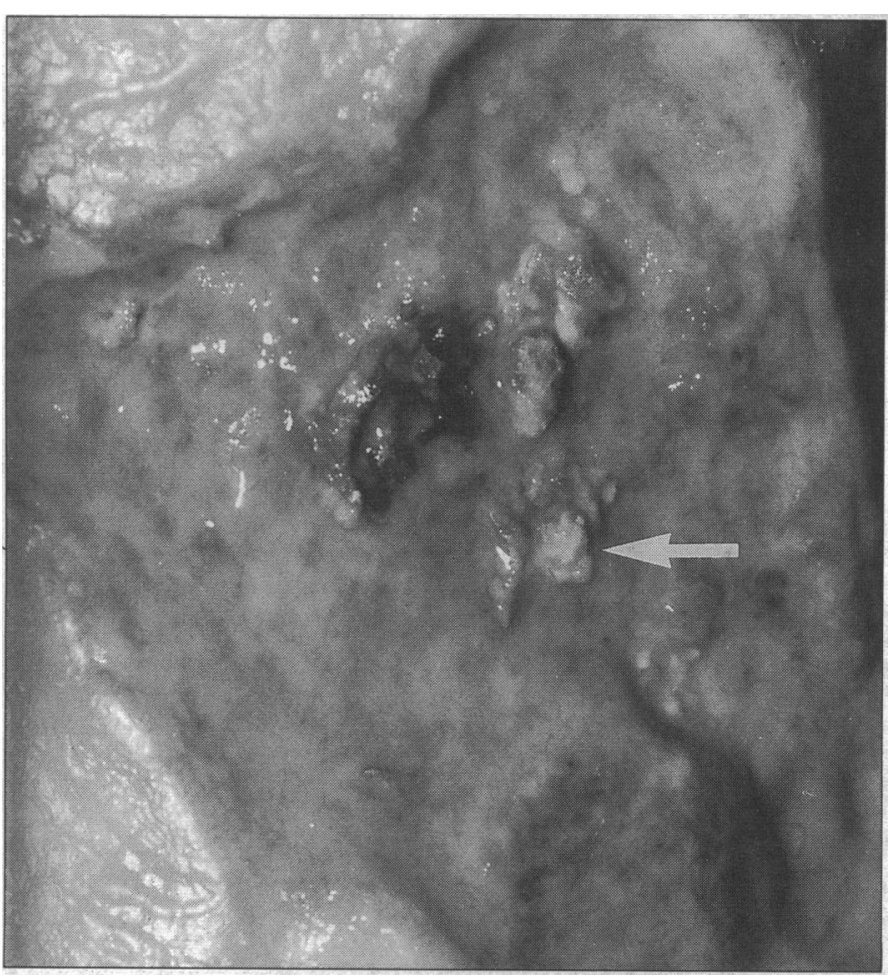

\section{Stones associated with leg ulcers}

A 92 year old woman with a 15 year history of varicose leg ulcers complained that the ulcers periodically extruded stones (figure). Chemical analysis of these stones showed their composition to be calcium oxalate and phosphate. Her serum calcium and phosphate concentrations and alkaline phosphatase activity were normal. $x$ Ray pictures showed extensive subcutaneous calcification in both legs, and a computed tomogram showed multiple subcutaneous calcifications in both calves.

Subcutaneous calcification is a well recognised complication of varicose ulceration, ${ }^{1}$ and this patient's stones seemed to be small pieces of calcification that had come to the surface. This phenomenon has been described only rarely. - P G FLANAGAN, $R$ W STOUT, J T LAWSON, department of geriatric medicine, Queen's University of Belfast, Belfast BT9 7BL

1 Lipman HI, Goldin RR. Subcutaneous ossification of the legs in chronic yenous insufficiency Radiology 1960;74:279-88.

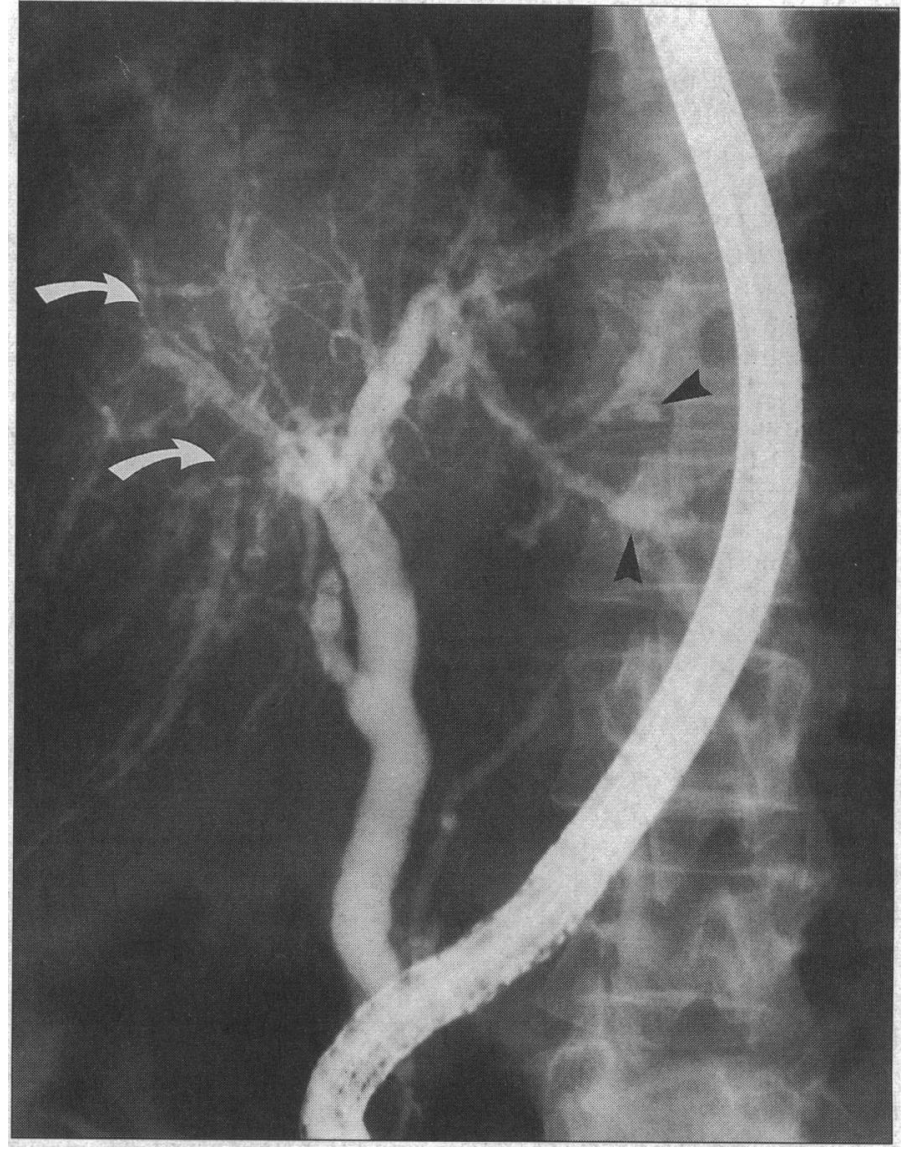

\section{Self injection treatment for impotence}

A 55 year old man with incomplete paraplegia presented with impotence. Intracorporeal injection of $60 \mathrm{mg}$ papaverine hydrochloride resulted in a full erection, and he started a self injection programme with $30 \mathrm{mg}$. His general practitioner was informed and asked to continue the prescription. After his first home injection he became unconscious but fortunately was found by the district nurse. On admission it became apparent that papaveretum $30 \mathrm{mg}$ had been dispensed, and after being given $0.4 \mathrm{mg}$ naloxone he recovered. Intrapenile injection of vasoactive compounds is a recent innovation, ${ }^{12}$ but to our knowledge this is the second instance of patients obtaining papaveretum; on the first occasion the patient realised the mistake before injection. This second occurrence was due to an error by the dispensing pharmacy. Similar errors in patients using up to $60 \mathrm{mg}$ may be fatal. As the use of this treatment for impotence increases attention to detail is obviously required. $-\mathrm{L}$ Q ROBINSON, T P STEPHENSON, Department of Urology, Cardiff Royal Infirmary, Cardiff CF2 1SZ

1 Virag R. Intracavernous injection of papaverine for erectile failure. Lancet 1982;ii:938. 2 Brindley GS. Cavernosal alpha-blockade: a new technique for investigating and treating erectile failure. Br f Psychiatry 1983;143:332-7.

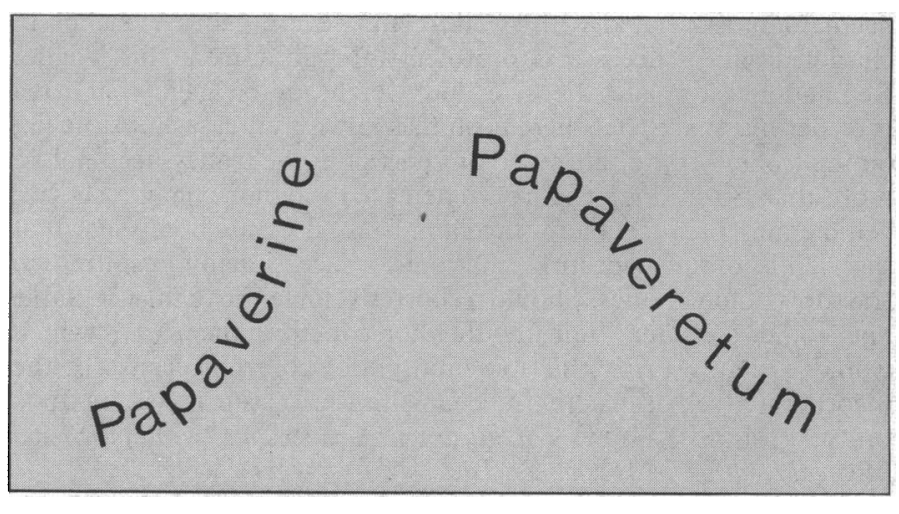

